\title{
МЕТОД ВИБОРУ ОПТИМАЛЬНОГО СПІВВІДНОШЕННЯ МІЖ ПОЧАТКОВИМ РІВНЕМ ТОЧНОСТІ ТА ЗАПАСОМ МЕТРОЛОГІЧНОЇ НАДІЙНОСТІ ВИМІРЮВАЛЬНОГО КАНАЛУ КОНТРОЛЬНО- ВИПРОБУВАЛЬНОЇ СТАНЦІЇ ПРИ ОБМЕЖЕННІ ВАРТОСТІ
}

У статті розроблено метод вибору оптимального співвідношення між початковим рівнем точності та запасом метрологічної надійності вимірювальних каналів контрольно-випробувальної станиії, щуо враховує характер змінювання у часі метрологічних характеристик та дозволяє забезпечити вимоги щздо обмеження вартості вимірювальних каналів контрольно-випробувальної станиії. Досліджені можливі для виробника иляхи забезпечення довгострокової метрологічної справності вимірювальних каналів контрольно-випробувальної станції. Це забезпечення достатнього запасу метрологічної надійності при виготовленні контрольно-випробувальної станиії та забезпечення "запасу на старіння” у вигляді достатньої величини запасу нормований межі допустимої похибки по відношенню до ї̈ фактичного значення. Проаналізовано характер зростання похибки вимірювального каналу контрольно-випробувальної станції та наведена типова залежність похибки вимірювальних каналів контрольно-випробувальної станції у часі. При виборі оптимального співвідношення між запасом метрологічної надійності $i$ запасом точності враховано суттєву відмінність вартості забезпечення метрологічної надійності вимірювальних каналів контрольно-випробувальної станцї із позитивним і негативним прискоренням старіння, щчо дозволяє зменшити витрати при побудові та експлуатації контрольно-випробувальної станції. Отримані відношення можуть бути використані при проектуванні контрольно-випробувальної станиії та ї̈ оптимізації за вартісним критерієм.

Ключові слова: контрольно-випробувальна станція, вимірювальний канал, метрологічна надійність, похибка.

\section{Вступ}

Засоби протиповітряної оборони є одним 3 найбільш високотехнологічних та високовартісних видів озброєнь. Для забезпечення прикриття від засобів повітряного нападу противника Збройним Силам України потрібна достатня кількість зенітно-ракетних комплексів (ЗРК), забезпечити готовність яких при обмеженому фінансуванні можливо тільки проведенням ремонту та модернізацією існуючих ОВТ радянського виробництва [1]. Контроль готовності ЗРК проводиться під час регламентних та контрольновипробувальних робіт з зенітними керованими ракетами (ЗКР) контрольно-випробувальними станціями (КВС), які є невід'ємною складовою частиною ЗРК, та які також модернізуються одночасно з ЗРК [2].

Постановка проблеми. Під час модернізації ЗРК радянського виробництва елементна база радіоелектронної апаратури замінюється майже повністю [2], що вимагає проведення вимірювань під час контрольно-випробувальних робіт 3 меншими похибками. Підвищення вимог до точності вимірювань параметрів ЗКР має наслідком застосування якісно нових та удосконалених КВС. Але, як правило, ускладнення КВС супроводжується зменшенням їх надійності. Для КВС, в основі роботи яких є вимірювання параметрів ЗКР, важливе значення має метрологічна надійність (МН), яка характеризує вимірювальні канали (ВК) КВС, перш за все - як засоби вимірювань. Від якості КВС, зокрема, від їх МН та стабільності метрологічних характеристик (MX), значною мірою залежать оперативність, необхідні точність і достовірність інформації про готовність ЗКР. Тому модернізація КВС та покращення їх якісних характеристик, та забезпечення довгострокової метрологічної справності є актуальною проблемою.

Аналіз останніх досліджень і публікацій. ЗКР $\epsilon$ складною технічною системою, яка характеризується різноманітними показниками, які необхідно контролювати під час експлуатації [3]. Розробкою методів технічної експлуатації ЗКР і підтримання технічної готовності ЗРК займались автори $[4,5]$. Удосконаленням теорії $\mathrm{MH}$ займались багато вчених: у роботах А.Е. Фрідмана [6], T.I. Чернишової [7], М.Ю. Яковлева [8] закладено наукову основу подальшого розвитку методів підвищення МН засобів вимірювальної техніки [9].

Але у розглянутих джерелах питання, які пов'язані з обгрунтуванням вибору оптимального співвідношення між запасом МН та запасом точності ВК КВС ще не розглядались.

Метою статті $\epsilon$ розробка методу вибору оптимального співвідношення між запасом точності та запасом метрологічної надійності ВК КВС при обмеженні вартості. 


\section{Виклад основного матеріалу} дослідження

Вимірювальний канал КВС є справним, якщо усі його нормовані МX відповідають значенням, що вказані у нормативно-технічної документації. Але у процесі експлуатації MX і параметри ВК КВС змінюються. Ці зміни носять випадковий монотонний характер і призводять до відмов, які поділяються на не метрологічні і метрологічні. Не метрологічні відмови обумовлені причинами, що не пов'язані зі зміною МХ ВК КВС, тому носять явний характер, проявляються раптово і можуть бути виявлені без проведення повірки.

Метрологічною називається відмова, викликана виходом MX за допустимі межи. Як показують проведені дослідження [11], метрологічні відмови трапляються значно частіше, ніж не метрологічні, причому найчастіше ці відмові є поступовими та характеризується монотонною зміною однієї або декількох МX. За характером прояву поступові відмови $\epsilon$ прихованими і можуть бути виявлені тільки за результатами періодичного контролю ВК КВС під час їх метрологічного обслуговування.

Процеси метрологічного старіння є причиною того, що з плином часу похибки ВК КВС неминуче зростають. Ці процеси відбуваються в основному на молекулярному рівні і не залежать від того, чи знаходиться КВС в експлуатації або на зберіганні. Тому поняття "напрацювання у включеному стані", для ВК КВС не має сенсу, оскільки пристрої схильні до старіння практично однаково як у включеному стані, так і при зберіганні. Таким чином, основним фактором, що визначає старіння $\mathrm{BK} \mathrm{KBC}, \epsilon$ календарний час 3 моменту виготовлення КВС.

Найпоширеним практичним способом забезпечення визначеного терміну метрологічної справності ВК КВС $є$ забезпечення достатнього “запасу на старіння” при побудові вимірювальних пристроїв КВС. Тобто, основним параметром, що у першу чергу визначає довгострокову метрологічну справність ВК КВС і на що може впливати виробник КВС, $\epsilon$ величина запасу нормований межі допустимої похибки по відношенню до ऑii фактичного значення при виготовленні КВС. Поступове витрачання цього “запасу на старіння" i забезпечує ВК КВС довготривалу метрологічну справність. На практиці виробники забезпечують приблизно двох-кратний запас нормованої межі похибки ВК КВС порівняно 3 іiі визначеним значенням (забезпечують надлишкову порівняно 3 нормованої точність вимірювального пристрою).

3 урахуванням цього неминучого старіння завод виробник у нормативно-технічної документації основну похибку пристрою встановлює приблизно 3 двохкратним запасом. Наприклад, якщо експериментально встановлено клас точності засобу вимірювання 0.2 , то у нормативно-технічної документації вказується клас точності 0.5. Але побудова вимірювальних пристроїв 3 надмірно високим фактичним класом точності (що за своєю фактичною стабільністю відповідає нижчому класу точності) також $\epsilon$ причиною зайвих витрат.
Час, протягом якого буде витрачено запас початковій точності ВК КВС у порівнянні 3 нормованою межею, залежить не тільки від величини цього запасу, але і від швидкості його витрачання, яка залежить перш за все від якості матеріалів i технології виготовлення вимірювального пристрою. Ця швидкість витрачання точності (запасу нормований межі допустимої похибки по відношенню до іiі фактичного значення) визначається метрологічною надійністю (МН) ВК КВС.

Метрологічна надійність - це властивість зберігати встановленні значення МX протягом певного часу при нормальних режимах та робочих умовах експлуатації. МН оцінюється часом, на протязі якого виконується ця вимога та може характеризуватися інтенсивністю відмов, ймовірністю безвідмовної роботи та напрацюванням на відмову [12,13]. Необхідний рівень МН може забезпечуватися шляхом вибору оптимального схемного рішення вимірювального пристрою за показником МН, вдосконаленням технології виготовлення, вибором надійної елементної бази [10], введенням надлишковості (резервування) як на рівні всього вимірювального пристрою, так і окремих його вузлів та елементів.

Старіння елементної бази ВК КВС є причиною підвищення частоти метрологічних відмов, та, відповідно, ремонтних витрат. Цей процес протікає повільно, його експериментальне дослідження можливо тільки протягом тривалого часу. У зв'язку з цим великого значення набувають математичні методи прогнозування процесу старіння. Теоретично МН можна знайти шляхом знаходження початкових змін МX i побудові математичної моделі, яка екстраполює отримані результати на великий інтервал часу. Зміни у часі MX ВК КВС $є$ випадковим процесом, тому основним інструментом побудови математичних моделей процесу старіння $€$ теорія випадкових процесів.

Для розв'язання задачі оцінки МН автором [14] запропонований критерій оцінки справності засобів вимірювальної техніки - запас $\mathrm{MH}$, якій зручно використовувати під час проектування та побудові ВК КВС, оскільки поступове витрачання цього запасу МН також забезпечує на певний період експлуатації (як і запас точності) метрологічну справність ВК КВС.

На практиці після метрологічної відмови виконується ремонт ВК КВС, але вже без забезпечення необхідного запасу на старіння. У найпростішому випадку графік зростання похибки у межах міжповірочного інтервалу $\epsilon$ лінійним (рис. 1). Якщо ремонт ВК КВС виконаний без запасу на старіння ВК КВС, то необхідно їх повторно ремонтувати майже щороку, внаслідок чого витрати на ТОіР значно збільшуються [15].

Зміна у часі верхньої 95\%-ної квантилі випадкового нестаціонарного процесу зміни похибки ВК, коли при кожної метрологічної відмові проводиться ремонт ВК і його похибка знову повертається до початкового значення $\gamma_{0}$, зображена на рис. 1 у вигляді ламаної лінії 1. Тут за кожен міжремонтний період 
$\mathrm{T}_{\mathrm{pi}}=\mathrm{t}_{\mathrm{pi}}-\mathrm{t}_{\mathrm{p} ; \mathrm{i}-1} ; \quad$ похибка $\quad$ ВК $\quad \gamma_{0}$ збільшується на $\gamma_{c ̧}$ (запас нормованої межі допустимої похибки по відношенню до $\gamma_{0}$.

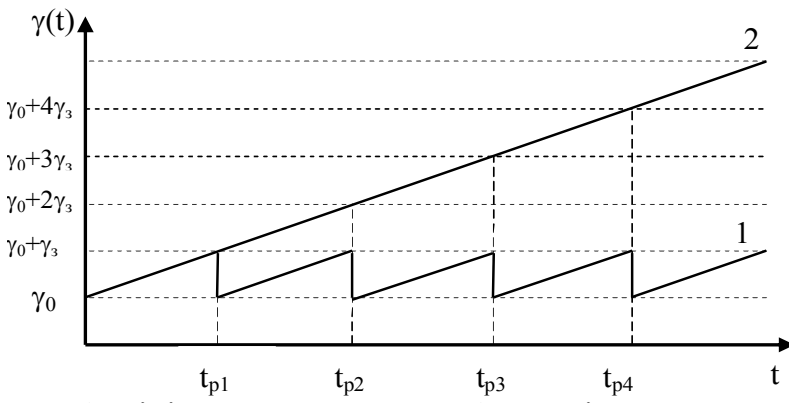

Рис. 1. Лінійне зростання похибки вимірювального каналу контрольно-випробувальної станції

Якщо метрологічні ремонти не проводити, то похибка ВК буде зростати безперервно за виразом:

$$
\gamma(\mathrm{t})=\gamma_{0}+\mathrm{n} \gamma_{c ̧},
$$

де $\mathrm{n}$ - кількість метрологічних ремонтів.

При збільшенні похибки ВК за лінією 2 всі міжремонтні інтервали $\mathrm{t}_{\text {pi }}$ будуть однаковими, як i i частота метрологічних відмов $\varpi_{\text {iâ }}=\frac{1}{\mathrm{~T}_{\mathrm{p}}}$ буде незмінною протягом усього терміну експлуатації КВС.

Але у житті все складніше i процес метрологічного старіння частіш за все має нелінійний характер [11]. Похибка 3 часом може прискорюватися, (прискорення метрологічного старіння характерно для вимірювальних пристроїв, які $\epsilon$ технічно складними та високотехнологічними), тому кожний наступний міжремонтний інтервал буде коротшим за попередній i частота метрологічних відмов 3 плином часу буде зростати (рис. 2).

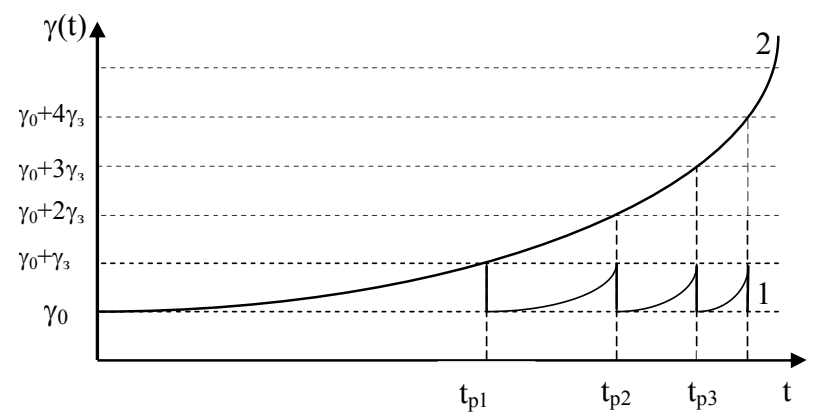

Рис. 2. Позитивне прискорення зростання похибки вимірювального каналу контрольновипробувальної станції

Та навпаки, при уповільненні 3 часом зростання похибки ВК (рис. 3), кожний наступний міжремонтний інтервал буде довший за попередній, а останній 3 них буде тривати до нескінченності. У цьому випадку частота метрологічних відмов буде спадати з плином часу аж до $\varpi_{\text {iâ }}=0$, тобто до припинення подальших метрологічних відмов.

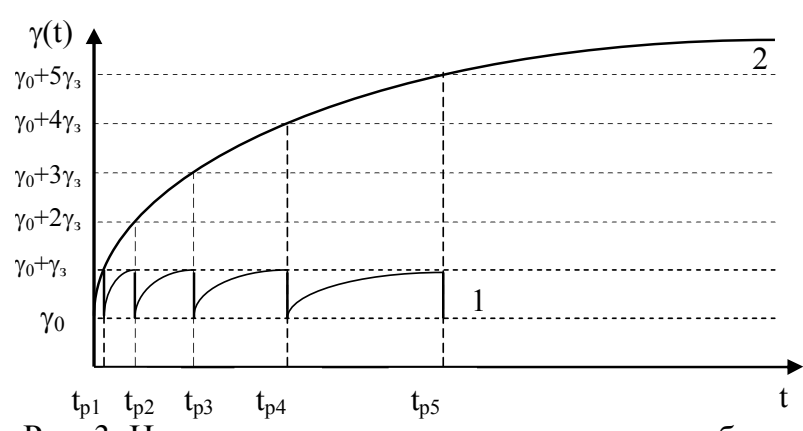

Рис. 3. Негативне прискорення зростання похибки вимірювального каналу контрольновипробувальної станції

Порівняння рисунків 1, 2 та 3 дає простий спосіб визначення наявності і динаміки процесу метрологічного старіння пристроїв. У залежності від характеру досліджуваного нестаціонарного випадкового процесу зростання похибки у часі i частота метрологічних відмов для групи однотипних вимірювальних пристроїв у складі ВК КВС буде різними. Якщо протягом інтервалу часу, який відповідає терміну експлуатації КВС, частота метрологічних відмов вимірювальних пристроїв $\epsilon$ приблизно однаковою як на початку так і в кінці цього інтервалу, то можна вважати, що процес старіння протікає лінійно. Якщо ж виявиться, що частота відмов на початку інтервалу помітно нижче, ніж в його кінці, то згідно рис. 2 це говорить про прискорення наростання похибки у часі. Зниження частоти метрологічних відмов протягом зазначеного (досить великого) інтервалу часу може бути наслідком уповільнення наростання похибки у часі (рис. 3).

Запропонований спосіб аналізу характеру процесу старіння пристроїв дозволяє при відносно малих витратах визначити динаміку процесу метрологічного старіння пристроїв без обробки масивів даних, що відповідають усередненню багаточисельних реалізацій нестаціонарного випадкового процесу старіння ВК КВС.

Як правило, для технічно складних та високотехнологічних ВК КВС характерне позитивне значення прискорення старіння. Їх висока точність супроводжується низькою МН, та подальше підвищення точності досягається більшими витратами, ніж відповідне підвищення запасу МН ВК КВС. Виникає завдання вибору оптимального співвідношення запасу початкової точності і МН ВК КВС при обмеженні витрат.

Оптимальне відношення показника запасу МН

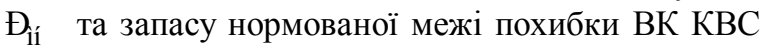
$\gamma_{c ̧}$, що забезпечує заданий час напрацювання до метрологічної відмови $\mathrm{O}_{\text {iâ }}$, отримаємо 3 умов:

$$
\begin{gathered}
\mathrm{T}_{\mathrm{I} \hat{\mathrm{A}}} \geq \mathrm{T}_{\text {İ̂Ầàä }} ; \\
\tilde{\mathrm{N}}_{\Sigma}=\left\{\tilde{\mathrm{N}}_{\mathrm{B}}+\tilde{\mathrm{N}}_{\text {İêlấ }}\right\} \leq \mathrm{C}_{\text {çàä }},
\end{gathered}
$$

де $\tilde{\mathrm{N}}_{\text {çàä }}$ - задане значення витрат на побудову та експлуатацію ВК КВС;

$\mathrm{C}_{\Sigma}$ - загальні витрати на побудову та експлуатацію ВК КВС;

$\tilde{\mathrm{N}}_{\mathrm{B}}$ - вартість побудови ВК КВС 3 урахуванням встановленого наробітку на відмову; 
$\mathrm{C}_{\text {МлОб }}$ - витрати на МлОб ВК КВС.

Дослідження показали [8], що у середньому зниження швидкості зростання похибки при побудові засобів вимірювальної техніки військового призначення за рахунок збільшення запасу МН обходиться у 1,5 раз дорожче, ніж за рахунок підвищення їх точності. Тому можливо скоротити витрати на побудову КВС лише за рахунок зміни правил нормування початкової точності ВК КВС, без будь-яких змін конструкції BK КBC.

Типова залежність похибки вимірювального пристрою у складі ВК КВС у часі наведена на рис. 4. Якщо цей ВК КВС мав би тільки позитивне прискорення старіння, то його крива $\gamma(\mathrm{t})$ не мала б горизонтальної ділянки на рівні 1,08\%. Цей вимірювальний пристрій може бути нормований так: вимірювальному пристрою присвоюється клас точності 0.5, але користувач попереджається про те, що він буде мати експлуатаційні витрати на метрологічну перевірку 4 рази на рік, а потім і частіше 3 метрологічними ремонтами; або вимірювальному пристрою присвоюється клас точності 0.7, а витрати користувача визначаються лише щорічними метрологічними перевірками i метрологічними ремонтами спочатку раз на 3 роки, а потім і частіше; або вимірювальному пристрою присвоюється клас точності 1.0, а частота метрологічних ремонтів зростає, починаючи 3 одного ремонту на 5 років.

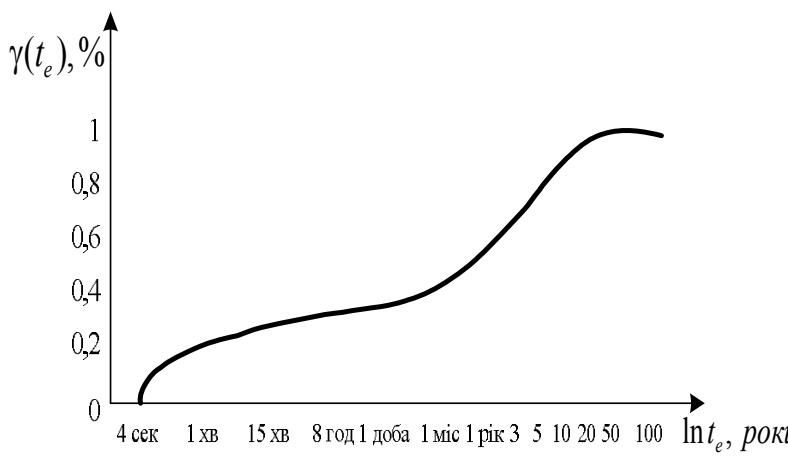

Рис. 4. Приклад зростання похибки вимірювального каналу контрольновипробувальної станції у часі

Для користувача це були б три вимірювальних пристрою різних класів точності, 3 різними експлуатаційними витратами на підтримку нормованої точності. Проте ціна цих вимірювальних пристроїв відрізняється незначно, оскільки для виробника вони відрізняються лише різними класами точності.

При виборі оптимального співвідношення між запасом МН і запасом точності слід враховувати суттєву відмінність вартості їх забезпечення 3 позитивним та негативним прискоренням старіння. При обгрунтуванні ціни ВК КВС необхідно приймати до уваги умови $(2,3)$, у цьому випадку розробникам буде економічно невигідно допускати заниження похибки ВК КВС 3 позитивним прискоренням процесу старіння i, навпаки, занижувати показники МН з негативним прискоренням процесу старіння, що, нажаль, є на практиці. $€$ економічно недоцільним заниження похибки ВК КВС з позитивним прискоренням процесу старіння, що також могло б привести до скорочення кількості метрологічних ремонтів. Тому використання при обгрунтуванні ціни ВК КВС умов (2, 3), що сукупно враховують початкову точність i запас $\mathrm{MH}$, забезпечить підвищення якості при обмеженому фінансуванні побудови ВК КВС.

Дрейф MX $\mathrm{y}(\mathrm{t})$ ВК КВС можна знайти за виразом [8]:

$$
\mathrm{y}(\mathrm{t})=\mathrm{m}_{\mathrm{o}}(\mathrm{t}) \pm \mathrm{k} \sigma_{\mathrm{y}}(\mathrm{t}),
$$

де $\mathrm{k}$ - коефіцієнт, що обирається 3 урахуванням закону розподілу $\mathrm{MX}$;

$\mathrm{m}_{\mathrm{o}}(\mathrm{t})$ - математичне сподівання МХ ВК КВС;

$\sigma_{\mathrm{y}}(\mathrm{t})$ - середнє квадратичне відділення МХ.

Прогнозування дрейфу МХ ВК КВС дозволяє

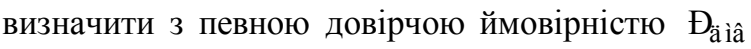
час появи метрологічної відмови $\mathrm{t}_{\text {iâ }}$. Величину інтервалу часу $\left(0, \mathrm{t}_{\mathrm{MB}}\right)$ будемо називати напрацюванням до метрологічної відмови ВК КВС Ò $_{\text {iâ }}$. Цей показник запасу MH визначає час роботи ВК КВС без метрологічних відмов. Тобто прогнозування дрейфу $\mathrm{MX} \mathrm{BK} \mathrm{KBC}$ дозволяє визначити напрацювання до метрологічної відмови для кожного конкретного типу ВК КВС.

Запас точності ВК КВС, що визначає необхідну величину запасу на старіння $\gamma_{c ̧}$, залежно від прогнозованого характеру іiі зміни (спадання або зростання), може бути обчислений за формулою:

$$
\gamma_{c ̧}=\left|y_{i ð} \pm m_{\dot{o}}(0)\right|, \text { iðè } \frac{\text { dó }(\mathrm{t})}{\mathrm{dt}}>0\left(\frac{\mathrm{dó}(\mathrm{t})}{\mathrm{dt}}<0\right) \text {. }
$$

Чим більший вибраний запас точності, тим більші при заданій швидкості зміни MX, що прогнозуються, напрацювання до метрологічної відмови $\mathrm{O}_{\mathrm{i} a ̂}$. Функції $\mathrm{m}_{\mathrm{y}}(\mathrm{t})$ i $\mathrm{y}(\mathrm{t})$ можливо отримати у результаті прогнозування стану МX ВК КВС та у залежності від характеру їх зміни можна збільшити напрацювання до метрологічної відмови $\mathrm{O}_{\mathrm{iâ}}$ ВК КВС шляхом коригування початкового рівня його точності. При цьому значення початкового рівня точності $\mathrm{m}_{\mathrm{y}}(0)$, a отже, і запасу точності ВК КВС для збільшення напрацювання до метрологічної відмови визначаються залежно від характеру прискорення зміни MX.

Таким чином, запропонований метод складається 3 чотирьох етапів: визначення характеру прискорення зростання похибки ВК КВС; розрахунку запасу точності ВК КВС; розрахунку запасу $\mathrm{MH} \mathrm{BK} \mathrm{KBC}$; знайдення оптимального співвідношення між початковим рівнем точності та запасом МН ВК КВС.

\section{Висновки та перспективи подальших досліджень}

Таким чином, вибір оптимального співвідношення між запасом точності і запасом метрологічної надійності ВК КВС у залежності від характеру прискорення процесу старіння ВК КВС дозволяє при фіксованих витратах на побудову та 
експлуатацію КВС збільшити час метрологічної справності ВК КВС. Знайдення вище зазначеного оптимального співвідношення 3 урахуванням прискорення старіння дозволить зробити практичний висновок, що, наприклад, забезпечення встановленого наробітку на метрологічну відмову ВК КВС економічно доцільно досягти для нескладних магнітоелектричних вимірювальних приладів збільшенням початкового рівня точності, а для високотехнологічних цифрових вимірювальних приладів - збільшенням запасу МH.

\title{
Литература
}

1. Карпенко Д.В. Стан та перспективи розвитку зенітного ракетного озброєння Повітряних Сил Збройних Сил України: Науковий журнал "Наука техніка Повітряних Сил Збройних Сил України”. 2017. № 2(27). С.75-78. 2. Бурковский С.И. Сравнительная оценка эффективности зарубежных вариантов модернизации ЗРК C-125M1 "Печора-М1" при решении задач ПВО важных государственных объектов Украины. [Текст] / С. И. Бурковский, П. Ю. Седышев // Системи озброєння і військова техніка. - 2010. - № 1(21). - С. 36 - 44. 3. Архангельский И.И. Проектирование зенитных управляемых ракет. / И. И. Архангельский П. П. Афанасьев, И. С. Голубев, В. Г. Светлов и др. - М.: МАИ, 2001. - 732 с. 4. Гриб Д.А. Удосконалення методів технічної експлуатації i ремонту як основа підтримання боєготового стану зенітного ракетного озброєння в сучасних умовах [Текст] / Д. А. Гриб, Б. М. Ланецький, В.В.Лук’янчук // Наука і оборона. 2012. - №3. - С. 55-63. 5. Пермяков О.Ю. Модель системи діагностування, технічного обслуговування та ремонту складних технічних систем військового призначення. / О. Ю. Пермяков, Ю. Б. Прібилєв, О. О. Дюбанов. // Наука і оборона. - 2016. - № 2. - С. 48-52. 6. Фридман А.Э. Метрологическая надежность средств измерений и определение межповерочных интервалов / Фридман А.Э. // Метрология. - 1991. - № 9 - С. 52 - 61. 7. Чернышова Т.И. Метрологическая надёжность средств неразрушающего контроля теплофизических свойств материалов и изделий : дис. ... доктора техн. наук: 05.11.13 / Чернышова Т. И. Тамбов, 1995. - 196 с. 8. Яковлев М.Ю. Розвиток теорії метрологічної надійності засобів вимірювальної техніки військового призначення: дис. ... доктора техн. наук: 05.01.02 / Яковлев Максим Юрійович. - Львів, 2011. -

425 с. 9. Кононов В.Б. Обгрунтування доцільності проміжних контрольних перевірок для підвищення метрологічної надійності зразків контрольноперевірочної апаратури авіаційної техніки. / В.Б. Кононов, О.Б. Котов, А.Д. Полянська. // Системи управління, навігації та зв'язку, 2019, випуск 2(54) С.3741. 10. Прібилєв Ю.Б. Удосконалений метод забезпечення метрологічної надійності вимірювальних каналів контрольно-випробувальних станцій. Материали XIII международна научна практична конференция „Найновите постижения на европейската наука - 2017“ 15 - 22 юни 2017 г. Volume 8. София "Бял ГРАД-БГ" ООД 2017. - С. 31-39. 11. Новицкий П.В. Динамика погрешностей средств измерений. / П.В.Новицкий, И.Л.Зограф, В.С.Лабунец// Ленинград:

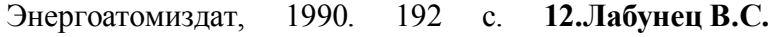
Разработка системы показателей метрологической надежности и исследование взаимосвязи технических, надежностных и стоимостных показателей электроизмерительных яри боров / Автореф. дис. на соиск. учен, степени канд. техн. наук, Ленинградский политехнический институт), 1976, 13 с. 13.Тарбеев Ю.В. Научно-технические перспективы обеспечения метрологической надежности средств измерений / Ю.В.Тарбеев, В.Н.Иванов, П.В.Новицкий // Измерительная техника. 1982. №5, С.17-19. 14.Ефремов Л.В. Запас метрологической надежности как критерий оценки исправности средств измерений. / Л.В.Ефремов // Изв. Вузов. Приборостроение. 2010. Т. 53, № 7 С.51-54. 15.Мищенко С.В., Цветков Э. И., Чернышова Т. И. Метрологическая надежность измерительных средств. / С.В.Мищенко, Э.И.Цветков, Т.И.Чернышова. // Москва: Машиностроение, 2001. $218 \mathrm{c}$.

\section{МЕТОД ВЫБОРА ОПТИМАЛЬНОГО СООТНОШЕНИЯ МЕЖДУ НАЧАЛЬНЫМ УРОВНЕМ ТОЧНОСТИ И ЗАПАСОМ МЕТРОЛОГИЧЕСКОЙ НАДЕЖНОСТИ ИЗМЕРИТЕЛЬНЫХ КАНАЛОВ КОНТРОЛЬНО-ИСПЫТАТЕЛЬНОЙ СТАНЦИИ ПРИ ОГРАНИЧЕНИИ СТОИМОСТИ}

\author{
Юрий Борисович Прибылев (кандидат технических наук, доцент)
}

\section{Национальный университет обороны Украины имени Ивана Черняховского, Киев, Украина}

В статье разработан метод выбора оптимального соотношения между начальным уровнем точности и запасом метрологической надежности измерительных каналов контрольноиспьтательной станции, учитьвающий характер изменения во времени метрологических характеристик и позволяющий обеспечить требования по ограничению стоимости измерительных каналов контрольно-испытательной станции. Исследованы возможные для производителя пути обеспечения долгосрочной метрологической работоспособности измерительных каналов контрольноиспьтательной станичи. Это обеспечение достаточного запаса метрологической надежности при изготовлении контрольно-испытательной станции и обеспечение "запаса на старение" в виде достаточной величины запаса нормированного предела допустимой погрешности по отношению к ее фактическому значению. Проанализирован характер роста погрешности измерительного канала контрольно-испытательной станщии и приведена типичная зависимость погрешности измерительных каналов контрольно-испытательной станции во времени. При выборе оптимального соотночения между запасом метрологической надежности и запасом точности учтено существенное отличие стоимости обеспечения метрологической надежности измерительных каналов контрольноиспытательной станции с положительным и отрицательным ускорением старения, что позволяет уменьиить затраты на построение и эксплуатацию контрольно-испытательной станции. Полученные отнотения могут быть использованы при проектировании контрольно-испытательной станции и ее оптимизации по стоимостному критерию. 
Ключевые слова: контрольно-испытательная станция, измерительный канал, метрологическая надежность, погрешность.

\title{
METHOD OF SELECTION OF OPTIMAL BALANCE BETWEEN THE LEVEL OF ACCURACY AND THE METROLOGICAL RELIABILITY OF THE MEASURING CHANNEL OF THE TEST STATION WITH THE LIMITING OF THE COST
}

Yurii Pribyliev (Candidate of Technical Sciences, Associate Professor)

\author{
National Defense University of Ukraine named after Ivan Cherniakhovsky, Kyiv, Ukraine
}

In the article there is developed the method of choosing the optimal correlation between the initial level of accuracy and the reserve of metrological reliability of measuring channels of the test station, which takes into account the nature of the time-varying metrological characteristics. Allows to provide requirements for limiting the cost of measuring channels of the test station. There are also investigated the possible ways for the manufacturer to ensure the long-term metrological efficiency of the measuring channels of the test station. This is provision of sufficient reserves of metrological reliability in the manufacture of test station and the provision of "stock on aging" in the form of a sufficient margin of stock is normalized limit of permissible error in relation to its actual value. The character of the increase in the error of the measuring channel of the test station is analyzed and the typical dependence of the error of the measuring channels of the test station in time is given. When choosing the optimal balance between the stock of metrological reliability and the precision reserve, a significant difference in the cost of providing the metrological reliability of the measuring channels of the test station with positive and negative accelerations of aging is taken into account, which allows to reduce the costs of construction of the test station. The obtained attitudes can be used for designing the test station and optimizing it according to the cost criterion.

Keywords: test station, measuring channel, metrological reliability, error.

\section{References}

1. Karpenko D.V. Stan ta perspektyvy rozvytku zenitnogho raketnogho ozbrojennja Povitrjanykh Syl Zbrojnykh Syl Ukrajiny: Naukovyj zhurnal "Nauka i tekhnika Povitrjanykh Syl Zbrojnykh Syl Ukrajiny”. 2017. №2(27). S.75-78. 2. Burkovskiy S.I. Sravnitelnaya otsenka effektivnosti zarubezhnyih variantov modernizatsii ZRK S-125M1 "Pechora-M1" pri reshenii zadach PVO vazhnyih gosudarstvennyih ob'ektov Ukrainyi. [Tekst] / S. I. Burkovskiy, P. Yu. Sedyishev // Sistemi ozbroEnnya I vIyskova tehnIka. - 2010. - \# 1(21). - S. 36 - 44. 3. Arkhangheljskyj Y. Y. Proektyrovanye zenytnыkh upravljaemыkh raket. / Y. Y. Arkhangheljskyj P. P. Afanasj'ev, Y. S. Gholubev, V. Gh. Svetlov y dr. M.:MAY, 2001. - 732 s. 4. Ghryb D. A. Udoskonalennja metodiv tekhnichnoji ekspluataciji i remontu jak osnova pidtrymannja bojeghotovogho stanu zenitnogho raketnogho ozbrojennja v suchasnykh umovakh [Tekst] / D. A. Ghryb, B. M. Lanecjkyj, V. V. Luk'janchuk // Nauka i oborona. 2012. - №3. - S. 55-63. 5. Permjakov O. Ju. Modelj systemy diaghnostuvannja, tekhnichnogho obslughovuvannja ta remontu skladnykh tekhnichnykh system vijsjkovogho pryznachennja. / O. Ju. Permjakov, Ju. B. Pribyljev, O. O. Djubanov. // Nauka i oborona. - 2016. №2. - S. 48-52. 6. Fridman A.E. Metrologicheskaya nadezhnost sredstv izmereniy i opredelenie mezhpoverochnyih intervalov / Fridman A.E. // Metrologiya. - 1991. - \# 9-S. 52 - 61. 7. Chernyishova T.I. Metrologicheskaya nadYozhnost sredstv nerazrushayuschego kontrolya teplofizicheskih svoystv materialov i izdeliy : dis. ... doktora tehn. nauk: 05.11.13/ Chernyishova T. I. - Tambov, 1995. - 196 s. 8. Jakovlev M.Ju. Rozvytok teoriji metrologhichnoji nadijnosti zasobiv vymirjuvaljnoji tekhniky vijsjkovogho pryznachennja: dys.
... doktora tekhn. nauk: 05.01.02 / Jakovlev Maksym Jurijovych. - Ljviv, 2011. - 425 s. 9. Kononov V.B. Obgruntuvannja dociljnosti promizhnykh kontroljnykh perevirok dlja pidvyshhennja metrologhichnoji nadijnosti zrazkiv kontroljno-perevirochnoji aparatury aviacijnoji tekhniky. / V.B. Kononov, O.B. Kotov, A.D. Poljansjka. // Systemy upravlinnja, navighaciji ta zv'jazku, 2019, vypusk 2(54) S.37-41. 10.Pribyljev Ju.B. Udoskonalenyj metod zabezpechennja metrologhichnoji nadijnosti vymirjuvaljnykh kanaliv kontroljno-vyprobuvaljnykh stancij. Materyaly KhIII mezhdunarodna nauchna praktychna konferencyja „Najnovyte postyzhenyja na evropejskata nauka - 2017“ " $15-22$ juny 2017 gh. Volume 8. Sofyja "Bjal GhRAD-BGh" OOD 2017. - S. 31-39. 11. Novitskiy P.V. Dinamika pogreshnostey sredstv izmereniy. / P.V.Novitskiy, I.L.Zograf, B.C.Labunets// Leningrad: Energoatomizdat, 1990. 192 s. 12. Labunets V.S. Razrabotka sistemyi pokazateley metrologicheskoy nadezhnosti i issledovanie vzaimosvyazi tehnicheskih, nadezhnostnyih i stoimostnyih pokazateley elektroizmeritelnyih yari borov / Avtoref. dis. na soisk. uchen, stepeni kand. tehn. nauk, Leningradskiy politehnicheskiy institut), 1976, 13 s. 13. Tarbeev Yu.V. Nauchno-tehnicheskie perspektivyi obespecheniya metrologicheskoy nadezhnosti sredstv izmereniy / Yu.V.Tarbeev, V.N.Ivanov, P.V.Novitskiy // Izmeritelnaya tehnika. 1982. \#5, S.17-19. 14. Efremov L.V. Zapas metrologicheskoy nadezhnosti kak kriteriy otsenki ispravnosti sredstv izmereniy. / L.V.Efremov // Izv. Vuzov. Priborostroenie. 2010. T. 53, \# 7 S.51-54. 15. Mischenko S.V., Tsvetkov E. I., Chernyishova T. I. Metrologicheskaya nadezhnost izmeritelnyih sredstv. / S.V.Mischenko, E.I.Tsvetkov, T.I.Chernyishova. // Moskva: Mashinostroenie, 2001. $218 \mathrm{~s}$. 